\title{
Correction to: The Role of Family Support in Facilitating Academic Success of Low-Income Students
}

\author{
Josipa Roksa ${ }^{1}$ D $\cdot$ Peter Kinsley ${ }^{2}$
}

Published online: 2 August 2018

(c) Springer Nature B.V. 2018

\section{Correction to: Research in Higher Education https://doi.org/10.1007/s11162-018-9517-z}

The original version of this article unfortunately contained a mistake in the acknowledgement section. Some of the vital information is missing in the published article. The complete information is presented with this erratum.

Acknowledgements This project would not be possible without the many agencies and individuals who contributed their time, advice, and resources to this endeavor. The authors are grateful to Sara GoldrickRab, Founder of the Wisconsin HOPE Lab; the Great Lakes Higher Education Guaranty Corporation; Greg Kienzl and the staff at ACT, Inc.; Eileen Horng at Evaluation and Assessment Solutions for Education; Wisconsin Higher Educational Aids Board staff; Peter Steiner at the University of Wisconsin; Wisconsin HOPE Lab staff members including Alison Bowman, Emily Brunjes Colo, Jed Richardson, Sara Sanders, Wanyi Chen; and John Stevenson and Tara Piche at the University of Wisconsin Survey Center. We are also deeply grateful to the staff at the financial aid, registrar, and institutional research offices at the institutions participating in the study. In addition, data collection for the project on which this paper is based was funded in part by the National Science Foundation grant to Sara Goldrick-Rab and Josipa Roksa (DUE-1317309). The views in this article are those of the authors and do not necessarily represent the views of the funding agency.

The original article can be found online at https://doi.org/10.1007/s11162-018-9517-z.

Josipa Roksa

jroksa@virginia.edu

Peter Kinsley

peter.kinsley@wisc.edu

1 Department of Sociology and Curry School of Education, University of Virginia, P.O.

Box 400766, Charlottesville, VA 22904, USA

2 University of Wisconsin-Madison, 231a Bascom Hall, Madison, WI 53706, USA 